\title{
The Anticipated Past in Historical Inquiry
}

A. O. Lovejoy, C. I. Lewis and E. Wind on Accounting for Knowledge of the Past Within a Pragmatist Theory

\section{Stefan Niklas}

\section{(2) OpenEdition}

1 Journals

Electronic version

URL: http://journals.openedition.org/ejpap/630

DOI: $10.4000 /$ ejpap.630

ISSN: 2036-4091

Publisher

Associazione Pragma

Electronic reference

Stefan Niklas, "The Anticipated Past in Historical Inquiry », European Journal of Pragmatism and

American Philosophy [Online], VIII-2 | 2016, Online since 16 January 2017, connection on 26 April 2019.

URL : http://journals.openedition.org/ejpap/630; DOI : 10.4000/ejpap.630

This text was automatically generated on 26 April 2019

\section{(c) $(1) \odot$}

Author retains copyright and grants the European Journal of Pragmatism and American Philosophy right of first publication with the work simultaneously licensed under a Creative Commons AttributionNonCommercial-NoDerivatives 4.0 International License. 


\section{The Anticipated Past in Historical Inquiry}

A. O. Lovejoy, C. I. Lewis and E. Wind on Accounting for Knowledge of the Past Within a Pragmatist Theory

\section{Stefan Niklas}

\section{AUTHOR'S NOTE}

I am very grateful for the invaluable comments by Tullio Viola and the anonymous reviewers which very much helped making my ideas clearer. I would like to warmly thank Annie Castro and Jono Taylor for reading the paper and improving my English.

\section{Introduction}

1 Historical inquiry presupposes the possibility of obtaining knowledge of the past. It thus implies (usually tacitly) an epistemology which can account for this kind of knowledge. However, the pragmatist theory of knowledge - especially as developed by Peirce or Dewey - is based on the anticipation of future events in order to verify or falsify the assumptions made. For this reason, serious doubts have been raised as to whether a pragmatist theory of knowledge is capable of accounting for historical knowledge at all: if knowledge is to be tested in the future, how can it possibly be tested by events which have already taken place in the past? Such doubts have been expressed quite meticulously by Arthur 0. Lovejoy, who was an important critical interlocutor of pragmatism, when this style of philosophizing became dominant in North-America in the early 20th century. The aftermath of Lovejoy's interventions can be observed in a number of reactions, including a response by Dewey which opened a debate between the two renowned philosophers in the Journal of Philosophy. ${ }^{1}$ However, instead of delving into this specific debate, I examine how C.I. Lewis dealt with the respective criticism while outlining his pragmatic theory of knowledge. In my view, Lewis's theory as presented in 
Mind and the World Order (1929) is the clearest and most comprehensive account on knowledge given from an enhanced pragmatist point of view. Although Lewis gives a formal answer to the problem of knowledge of the past, he is less concerned with the practice of historical inquiry. This omission by Lewis requires us to consider how the past is known through documents that are used as the epistemic instruments which make the past detectible. Edgar Wind's regrettably unheeded paper on "Some Points of Contact between History and Natural Science," produced in 1936, is concerned with precisely this issue.

2 Through a consideration of the related arguments of Lovejoy, Lewis and Wind, I suggest that a pragmatist theory of knowledge cannot only account for knowledge of the past in the first place, but can actually elucidate a basic epistemological feature of historical inquiry: Knowledge of the past can only be gained by means of anticipation.

\section{Lovejoy's Criticism}

\section{a) Arthur O. Lovejoy as a Critical Interlocutor of Pragmatism}

3 The role of Arthur O. Lovejoy in the history of pragmatism is that of a provoking and belligerent, though still somehow appreciative (but in any case critical), interlocutor of the movement. His criticism is noteworthy not least because it was effective within the pragmatist tradition itself: Lovejoy provoked a great deal of response (direct or indirect) from those who considered themselves to be pragmatists - including Dewey and reportedly James - and thus influenced the development of this very movement. Lovejoy's critical contribution - which centered on his calls for greater clarification of the basic concepts of pragmatism as a consistent doctrine - is commonly associated with two works: his notorious paper on "The Thirteen Pragmatisms," published in two parts in 1908, and a chapter on "Pragmatism Versus The Pragmatist" from 1920. Although Lovejoy's later contribution presents a much more elaborate attempt of criticism and led to a direct debate with Dewey, his paper on the "Thirteen Pragmatisms," or at least its brusque title, has, until recently, been received more intensely. ${ }^{2}$ The general aim of Lovejoy's attacks is to offer "a species of Prolegomena zu einem jeden künftigen Pragmatismus " (Lovejoy 1908: 39) ${ }^{3}$ and to rectify what he considers to be the crucial selfmisunderstandings of this otherwise promising kind of philosophy. The yardstick of this criticism is the idea of a consistent doctrine that pragmatism should become, and which shall be defended against "the pragmatist's" assumed readiness to affiliate his position to various doctrines. I say "his," because in Lovejoy's paper from 1920 "the pragmatist" is exclusively identified with Dewey as the main representative of this current.

4 At the outset of his article on "Pragmatism Versus The Pragmatist" ${ }^{4}$ Lovejoy takes pains to detect the steady position of pragmatism between idealism and realism, which he regards as the mutually exclusive foundations of presumably any philosophical doctrine. However, this opposition rather reflects the situation of American philosophy at the beginning of the 20th century than a systematic necessity to keep realism and idealism as polar opposites. According to this presupposed opposition, pragmatism must either be a version of realism or of idealism (both either monistic or dualistic) ${ }^{5}$ - or it must present a third option. Lovejoy then devotes a great deal of his argument to a lengthy discussion of quotations from Dewey at different occasions (and partially taken out of context) to show how "the pragmatist" recurrently contradicts himself in a way that cannot be 
harmonized since his claims sometimes fall in the realist's and at other times in the idealist's camp. Apart from taking delight in deliberate provocation of the philosophic community, this exhibition of ambiguities in Dewey's writings serves Lovejoy to delineate the field of his aspired reassessment of pragmatism. In the center of this field he puts the problem of knowledge and approaches it with regard to the existence of mental entities and, more importantly, knowledge of the past.

\section{b) Lovejoy's Arguments against the Anticipatory Character of Knowledge}

5 While exploring the pragmatist's stance on the existence of mental entities, Lovejoy encounters anticipatory knowledge as a key concept in Dewey's theory ${ }^{6}$ and detects its importance for the close connection of knowledge and action which is indeed characteristic of philosophical pragmatism in general. Lovejoy takes the suggestions concerning the concept of knowledge, which Dewey presents most extensively in his Essays in Experimental Logic (2004), as a limited piece of descriptive psychology and attacks the assumption that every anticipated meaning is closely connected with an operation: "This amounts to an assertion that we never anticipate without proposing to ourselves some course of action with reference to the thing anticipated - an assertion which I take to be a false psychological generalization" (Lovejoy 1920: 52). He objects that there is also "passive" anticipation of future events (and even quotes James to support this view) and gives the example of "a windfall of fortune which one can do nothing - and therefore intends to do nothing - to bring about" (Lovejoy 1920: 52). The scenario that Lovejoy selects to illustrate his point, however, is not an example of knowledge - neither of knowledge about the event itself, nor about something else that would be rendered true or false by it - but instead refers to the mere hope for something to happen. Furthermore, the hope for this "windfall of fortune" is clearly concerning one's conduct until and after this event occurs.

6 Although the first objection is easily refutable, Lovejoy's second one is much more important and lies at the heart of his criticism. It concerns "Dewey's limitation of the 'knowledge-experience' exclusively to forward-looking thoughts," which, as Lovejoy rightly observes, means that Dewey "identifies all knowledge with anticipation" (Lovejoy 1920: 52). Lovejoy now tries to turn Dewey against himself - or "pragmatism" against "the pragmatist" - as he argues that this definition of knowledge "ignores the patent empirical fact that many of our 'meanings' are retrospective - and the specifically pragmatic fact that such meanings are indispensable in the planning of action" (Lovejoy 1920: 53). This point seems worthwhile since retrospection is indeed the very source of anticipation: Experiences we are presently having and those we are going to have are both informed by reference to former experiences, which are consequently the source out of which we first gain the assumptions to be tested as knowledge. Lovejoy acknowledges that Dewey is not actually arguing against this, and he even quotes one of Dewey's affirmative statements on this kind of inter-temporal cognition which explicitly emphasizes the meaning of retrospection. ${ }^{7}$ He still maintains, however, that Dewey is not systematically integrating retrospection into his theory of knowledge since anticipation remains the decisive element that defines knowledge within this theory.

7 If Lovejoy is right about the systematic lack of retrospection in Dewey's account, two mutually exclusive consequences are conceivable. One possibility is that Dewey's neglect 
indicates the "psychological" one-sidedness of his theory and must be rectified by introducing retrospection as a distinct mode of inter-temporal inference and the strict opposite of anticipation. Alternatively, Dewey's oversight can be explained by suggesting that anticipation, as the basic operational mode of knowledge, must somehow integrate (or overlap with) retrospection. Only the latter consequence could build on Dewey's conception of knowledge. Lovejoy's decision to only conceive of the former consequence forces him to opt for the replacement of Dewey's theory of knowledge by another, yet unspecified, theory. He does not even consider the possibility of anticipation as integrating retrospection and the associated possibility of the past as an object of anticipatory knowledge. Unfortunately, this prevents Lovejoy from asking the real question his criticism brings about: If all knowledge is contained in anticipatory or predictive judgments, this must also be true for knowledge of the past; but how is it possible to "anticipate" a past event in a judgment (without producing logical nonsense)? Lovejoy is not alone in failing to ask this question. Dewey, who fails to make the respective implications of his theory explicit, is also guilty of this oversight. Thus, Dewey passively facilitates misunderstandings such as Lovejoy's which culminate in the claim that "[t]he pragmatist [...] manifests a curious aversion from admitting that we have knowledge, and 'true' knowledge, about the past" (Lovejoy 1920: 63).

In order to achieve a more constructive understanding of how to approach the question how can the past be anticipated? - I will first consider Lovejoy's misunderstandings by examining the three explanations he provides when making sense of what he describes as Dewey's "strange disinclination to acknowledge the immense importance of retrospection" and "to recognize the possibility of veridical retrospection" (Lovejoy 1920: 63).

9 According to Lovejoy, the first reason is Dewey's "moral appraisal" of anticipation as serving creative intelligence more effectively than retrospection. It is true that Dewey's essay "The Need for a Recovery of Philosophy," which Lovejoy quotes in support of his accusation, carries such an overtly "moral" plea as regards the role of philosophy in society. It is also true that Dewey regards anticipation as "more primary than recollection" (Dewey 1917: 14) in the course of acting towards a goal - which is what creative intelligence is about. This is in fact how Dewey conceives the process of life, namely as the constant process of readjusting the relationship of organism and environment, something that involves the ongoing pursuit of an ever passing equilibrium. Within this bio-evolutionary view one must inevitably conceive "success and failure" of organic adaption as "the primary "categories' of life" (Lovejoy 1920: 14) ${ }^{8}$ and to hold that anticipation is the primary cognitive operation which obeys these "categories." In contrast to goal-oriented or problem-solving actions, operations of a more (self-) reflective character, like retrospection, appear "secondary" to the direct practical need for anticipation. One may or may not consent to the bio-evolutionary foundation of Dewey's philosophical outlook, but one cannot say that his prioritization of the anticipatory function was merely a moral postulate without any further (bio-) logical reason.

Dewey admits then that the "[i]maginative recovery of the bygone," which in Lovejoy's terms is retrospection, "is indispensable to successful invasion of the future, but its status is that of an instrument" (Lovejoy 1920: 14); it is subordinate to the more general operation of anticipation. Since Dewey's essay is about the "Recovery of Philosophy" he immediately tries to transpose this argument into the business of philosophy. The merits 
of the recovery of the bygone in the pursuit of knowledge remain unquestioned (and become apparent in Dewey's own work), but Dewey criticizes the tendency of his philosophical contemporaries "to isolate the past, dwelling upon it for its own sake and giving it the eulogistic name of knowledge" (Lovejoy 1920: 14). His attack is not, therefore, directed against recollection or recovery of the past in general, but against the habit of philosophical discourse to restrict itself to "traditional" problems of bygone times instead of applying the attitude of "normal" practical life - which is primarily based on the cognitive function of anticipation - to their own business. Dewey is guilty of moving from the level of the biological foundation of practical human conduct to his postulates and polemics concerning the deplorable condition of philosophy far too quickly, leaving certain steps of his argumentation to the reader. He thus, again, leaves room for the suspicion Lovejoy articulates.

Lovejoy then identifies the second reason "why retrospection is the Cinderella of the pragmatic theory of knowledge" (Lovejoy 1920: 65) in the problems that Dewey is understood to have in his concept of "the past" as such. Lovejoy observes that the pragmatist "finds it difficult to see how the data which serve in an inference can be unaffected by the intent of the inference and by the character of the particular situation in which the need for inquiry and inference originates" (Lovejoy 1920: 65), which I consider to be a generally satisfying description of the attitude of experimental logic. Lovejoy, however, holds that Dewey fails to acknowledge the fact that the past "is just blankly there, unmodifiable, irremediably external to the 'present concrete situation,' inaccessible to action either present or prospective" (Lovejoy 1920: 65). This statement, which is suggestive of an utterly un-critical realism, however, is at odds with the historian of ideas Lovejoy was. ${ }^{9}$ For if the past was blankly there, it would be either totally disclosed, wholly inaccessible to the inquiring mind (because the mind could not get " there"); or it would be totally open and accessible in every detail. Neither is the case. Since he does not further elaborate on the implications of this claim, it is not clear - but rather unlikely - that Lovejoy would really defend such a view of the past as the absolute totality of the bygone. Leaving Lovejoy's intentions aside, it is clear that Dewey's pragmatism does not in fact (and could not possibly) entail such a notion of the past. His theory of knowledge concerns knowledge as emerging from concrete "experimental" interaction, not from the abstract correspondence of internal assumptions with external facts (without knowing what mediates between them). Accordingly, knowledge of the past, pragmatically considered, can only be achieved through experimental interaction with instances of the past in a present concrete situation. Therefore, Lovejoy's negative assumption only reaffirms what Dewey's theory is compelled to presuppose, if this theory shall account for knowledge of the past, namely that the past is accessible to present and prospective action. (Further consequences of this claim will be discussed below in section III.)

12 The third reason, which Lovejoy regards as the principle reason for "the pragmatist's unwillingness to classify retrospection as true knowledge," concerns "that subjectivistic strain in his [the pragmatist's] thought" (Lovejoy 1920: 65). What Lovejoy has in mind here is the attitude of "radical empiricism" that was established by James and indeed became very influential within and beyond the pragmatist movement. Although this particular attitude does not - at least not necessarily - affect the more "instrumentalistic" views of Peirce and Dewey, Lovejoy thinks that pragmatism is altogether pervaded by it. ${ }^{10}$ By adopting this approach, Lovejoy, who once tried to show 
how many independent doctrines call themselves pragmatism, imposes one special doctrine upon all other modes of the pragmatic attitude. This false generalization represents a common mistake in the reception of pragmatism - which is why it is important to take a closer look at this aspect of Lovejoy's critique. He crudely presents empiricism as a theory which requires direct, i.e. subjective, experience as the precondition for establishing whether something can truly be known. Assuming that this is a claim which is more or less implied - though not consistently - in every pragmatist theory, Lovejoy starts to draw the respective consequences for the epistemic status of the past in "the pragmatist's" theory of knowledge. He writes:

The status of my past experience, from the point of view of a present judgment or inquiry concerning it, is precisely the same as the status of a contemporaneous but extra-subjective reality. Neither the one nor the other can now or hereafter be directly experienced; of neither is the reality accessible to verification. If, then, truth is an experienced relation, true judgments about the bygone are as impossible as true judgments about such 'transempirical' objects [...]; for the past term of the relation is also, qua past, a kind of 'transempirical' [...]. The past cannot be known because, since it is ex hypothesi now inaccessible to us. We can never compare it with our idea of it, nor determine which of our ideas of it are true or false. (Lovejoy 1920: 66)

The basis for this conclusion is a long quotation from Dewey's "A Short Catechism Concerning Truth" (1910) - but it is hard to see where in this piece Lovejoy finds the hypothesis he ascribes to Dewey. Dewey argues that the past, as with anything else that is not immediately present, becomes inaccessible if treated in abstraction from the concrete situation of a present inquiry. He attacks the "intellectualist" account of truth, by which he means a correspondence-theory of truth, for being unable to show how a judgment comes to land "straight on the devoted head of something past and gone" (Dewey 1910: 160) ${ }^{11}$ which is the reason why it is forced to talk about "transcendence." Against this Dewey defends a theory which takes "truth" to be a function of statements about events as distinguished from the events themselves. Accordingly, events only become "true" in terms of a judgment about them. ${ }^{12}$ Although at this point Dewey says nothing about how knowledge seeks access into events and objects which are not themselves present in a given moment, it does not follow that he denies the very possibility of such access - in fact, the opposite is the case.

What Lovejoy misconstrues in the above quotations is the very notion of experience on which pragmatism as instrumentalism is built. By regarding experience as thoroughly subjective - a position that may be commonly held, but is at odds with the pragmatist conception - he puts it in opposition to objective facts. Against this common misconception a counter-interpretation can be given: According to the experimental logic of inquiry, experience allows for the creation of criteria which make it possible to decide if a belief is supported by some kind of material evidence or not. And although it is impossible to subjectively experience the past event itself, this is not even necessary in order to have experiential access to it: The very existence of the past event in question as much as its relevant features (relevant in terms of the question asked about it) can be inferred from presently experienced events as signs. While this take on accessing the past remains implicit in Dewey's Essays in Experimental Logic, it becomes very clear in the introduction to the second edition of Experience and Nature from 1929 (which Lovejoy, admittedly, could not have known at the time). Here, Dewey gives the following example:

A geologist living in 1928 tells us about events that happened not only before he

was born but millions of years before any human being came into existence on this 
earth. He does so by starting from things that are now the material of experience. Lyell ${ }^{[13]}$ revolutionized geology by perceiving that the sort of thing that can be experienced now in operations of fire, water, pressure, is the sort of thing by which the earth took on its present structural forms [...]. The geologist did not leap from the thing he can see and touch to some event in by-gone ages; he collated this observed thing with many others, of different kinds, found all over the globe; the results of his comparison he then compared with data of other experiences, say the astronomer's. He translates, that is, observed coexistences into non-observed, inferred sequences. Finally he dates his object, placing it in an order of events. By the same sort of method he predicts [!] that at certain places some things not yet experienced will be observed, and then he takes pains to bring them within the scope of experience. (Dewey 1958: 4a)

This prediction of observability is another expression for the future consequences which prove the truth of an idea about a past event, as Dewey already put it in another passage of the "Catechism." ${ }^{14}$ In contrast to the ambiguities of the latter text, which is composed as a rather dogmatic (though somewhat ironically intended) dialogue between a teacher and a student, ${ }^{15}$ the passage from Experience and Nature makes very clear that the kind of experiences Dewey is concerned with are not private or merely subjective ones, but public or intersubjective. It also shows that "the past" is by no means an inaccessible realm of transempiricals, as Lovejoy is convinced the pragmatist was compelled to hold. It is only Lovejoy himself who is bound to such a static conception of the past since his correspondence-theory affords a comparison of an idea about the past with the past "itself" and thus makes the whole matter a question of metaphysical realism. ${ }^{16}$ As the example of the geologist - which vividly depicts the decisive trait of the pragmatist's take on knowledge - shows, however, the issue at stake relates to methodological principles of inquiry, i.e. about the epistemic techniques applied to a certain problem, rather than notions of abstract realism. These techniques do not simply presuppose the reality of past things as static comparable parameters "out there," they rather try to find out what can be conceived as real in the first place by compiling evidence and making inferences from it. In any inquiry of the past, and especially in historical inquiry, the reality of a past event is first of all an assumption that needs proof: Either the inquirer is already sure that something did happen (be it ten or a million years ago) and tries to find out what exactly it was and how it happened; or the inquirer asks whether an assumed event happened at all, and if not, what happened instead.

Now this instrumentalistic conception of a pragmatist theory of knowledge, which in fact can account for knowledge of the past, is free from any concession to "radical empiricism" and thus meets this crucial demand of Lovejoy's critique - while refuting his allegation concerning "the pragmatist's unwillingness to classify retrospection as true knowledge" (Lovejoy 1920: 65). Although Lovejoy's call for a general "rectification" of pragmatism and the respective theory of knowledge points in the wrong direction, he nevertheless brought to the fore the underlying question which is still left open: If knowledge is essentially anticipatory, how can the past be anticipated? Although my interpretation of Dewey's example from Experience and Nature seeks to steer the course of Dewey's theory into this direction, Lovejoy is surely right that "the time-distinctions pertinent to this inquiry" (Lovejoy 1920: 79) are not yet made precise. He is also right that Dewey's tendency to produce ambiguities in his writings which make it difficult - though not impossible - to reconstruct his theory of knowledge, especially without concessions to "subjectivism." Therefore, I will now turn to the most elaborate theory of knowledge provided by an adherent of the pragmatist tradition, a theory which is unambiguously 
opposed to the attitude of radical empiricism and at the same time acutely aware of the consequences of an anticipatory concept of knowledge. This theory has been provided by C. I. Lewis in terms of his "conceptual pragmatism."

\section{A Response by C. I. Lewis}

17 On the occasion of a meeting of the American Philosophical Association in New York City in 1929 Clarence Irving Lewis, who had recently published Mind and the World Order, looked back on the development of pragmatism and tried to place it within current thought. Without mentioning the name of Arthur O. Lovejoy, the infamous intervention of the "Thirteen Pragmatisms" serves Lewis as the starting point for his reflection: "That there should be thirteen distinguishable pragmatisms, however, is not a peculiarity: these could be set alongside the thirty-seven idealisms and fifty-one realisms" (Lewis 1970a: 78). He adds that "William James is reported to have said that he was pleased to find that pragmatism had this wealth of meaning; he accepted all thirteen. In any case, such variety merely marks the fact that pragmatism is a movement, not a system" (Lewis 1970a: 78). This movement, however, is not completely without a common denominator, although it cannot be fixed in a single claim: "Pragmatism is, as James indicated, not a doctrine but a method" (Lewis 1970a: 79), and the condensed principle of this method is the pragmatic test of significance, which refers to the difference a notion makes in terms of the pragmatic effects it bears (or does not bear).

While Lewis is stealing the thunder of Lovejoy's attacks and defends the idea of pragmatism as a method, it becomes clear from his talk (which was published in the Journal of Philosophy in 1930) that his own adherence to pragmatism is, however, not without reservations. These concern the "highly subjectivistic theory of knowledge as immediate" (Lewis 1970a: 81) one might arrive at, if the emphasis on the directly empirical receives too much weight. Lewis, in contrast, stresses the meaning of a functional theory of knowledge, which analyzes the use of concepts as the basic instruments of thinking - while leaving out the immediate altogether. "We must all be pragmatists," Lewis declares his conviction, "but pragmatists in the end, not in the beginning" (Lewis 1929: 267).

19 In this sense Lewis is taking up Lovejoy's demand for a pragmatism without radical empiricism. But in contrast to Lovejoy, Lewis also elaborates a positive vision of pragmatism as "conceptual pragmatism" which he presents as the Outline of a Theory of Knowledge (this is the subtitle of Mind and the World Order). This book presents a very unorthodox reading of and contribution to the pragmatist tradition since it does not only emphasizes the importance of conceptual interpretation, but also dares to reanimate the a priori as an indispensable element of knowledge. He thereby suggests a constructive way of dealing with topics which were usually attributed to idealism by giving them a pragmatic twist. Lewis holds, in short, that knowledge consists of two functional elements, the empirical and the a priori, of which only the a priori element is truly pragmatic. Before experience can even begin to be intelligible, it needs criteria (definitions, principles) supplied by deep-lying attitudes of thinking to interpret given presentations. These criteria determine "reality" which in Lewis' theory translates as "experience categorized" (Lewis 1929: 365). Consequently, these criteria of categorization are not derived from, but applied to concrete experience, giving some kind of order to it. Lewis does not claim that the a priori element in knowledge comes from above; on the 
contrary, he holds that the human mind determines the categories it uses relative to its purposes. The intension or intrinsic meaning of categories is stable, they are "absolute" as Lewis likes to put it in a certain idealist vocabulary, ${ }^{17}$ but they are constantly tested in application. If they do not serve the mind's purposes of making the empirical intelligible, they are discarded and replaced by others. Categories are restrictive, but their own boundaries in application are set by the "qualia of the given" (Lewis 1929: 157).$^{18}$ Thus the choice of categories - which is also contingent upon historical change as regards the actual set of accessible and plausible categories ${ }^{19}$ - is the fundamentally pragmatic aspect of knowledge. And every pragmatic choice of a certain category, i.e. every conceptual interpretation of something that is presented to the mind as given, implies a hypothesis about the anticipated outcome of its application.

As Lewis is very much aware, a theory which is based on an anticipatory concept of knowledge must also explain how it can account for knowledge of the past:

It is a frequent criticism of the type of theory here outlined that it cannot account for our knowledge of the past. Knowledge, it is said, is here identified with verification, and verification comes about by some proceeding from the present into the future. Thus the past, so far as it can be known, is transformed into something present and future, and we are presented with the alternatives, equally possible, that the past cannot be known or that it really is not past. (Lewis 1929: 149)

21 Although Lovejoy's name is again not explicitly mentioned, it is reasonable to assume that he is the author (or at least one of the authors) of the criticism Lewis rephrases here. Lewis seems to repeat the conclusion of Lovejoy's paper from 1920 as he admits that a complete answer to this criticism would require a metaphysical analysis of temporal categories. Instead of such a "complete" answer, Lewis presents several of considerations that serve as an epistemologically sufficient response. The initial consideration holds that to have knowledge of the past at all does not require to know everything that can possibly be known about the past: "If, then, we assert that, from the point of view of knowledge, the past is so and so, this is not to deny to the past various types of significance not included in such an epistemological account" (Lewis 1929: 150). Lewis starts with the simple fact that the past, or aspects of it, are in general verifiable - because "there could not be any item of the past which is intrinsically unverifiable." This verification can only happen in the present or future. It does not follow, however, that the past itself was thereby transformed into something present or future, as the critics - like Lovejoy - seem to suggest. It only means the assignment of a temporal locus to an object or event which is known by means of its effects. In Lewis' words: "The assumption that the past is intrinsically verifiable means that at any date after the happening of the event, there is always something, which at least is conceivably possible of experience, by means of which it can be known" (Lewis 1929: 151). Lewis calls this "something" the effects of the past event which endure after it has ceased to exist, and states that the "totality of such effects quite obviously constitute[s] all of the object that is knowable" (Lewis 1929: 151). My reading of Lewis' rather short remarks about these effects is that the way in which they represent the past object must be conceived as a material extension which is literally identified with the past object. To say the effect is identified with the past event does not mean it was identical with it - for the event and its extension are not simply the same. A finger print or a sample of DNA are not identical with the person who left it, still, the person and the print or sample are mutually identified: the one makes the other identifiable. Likewise, the fragments of a Roman temple are not strictly identical with the 
corresponding religion or the totality of the bygone Roman civilization, but, as the concrete parts of the whole, they are identifiable with reference to this religion and thus identify the very civilization which once settled here. Lewis' own way to make this point "that the event is spread throughout all after time" makes use of a comparison with modern physics where it is said that "the field of an electronic charge is spread through all space and that this field is the electron" (Lewis 1929: 151-2). Accordingly, what cognition apprehends in the enduring effects of a past event "and what historical knowledge proceeds to verify, is a part of its [i.e. the past event's] nature" (Lewis 1929: 152).

I read the predication expressed by "is" (as in "this field is the electron") and Lewis' reference to the "nature" of the event as a logical "is" and a functional "nature." Although the identity of present effects and past event means a material identity (instead of a formal, ultimately arbitrary representation), this identity is differential or partial: The effect does not exhaust the event, but it means the event since it belongs to it as one of its parts and thus concretely presents it. I regard this relation of effects and past events as a logical inseparable relation. Just like the present light of a collapsed star is logically inseparable from this very star which ceased to exist, a book written in a "dead" language is inseparable from the culture in which this language was a vital means of communication. Of course, taken merely as light or simply as a bulk of paper the meanings of these phenomena cannot be understood as the effects of something; but the moment they are comprehended as such evident effects of events that are temporally prior to them, they also become logically bound to these events. In other words, although the book can be seen in abstraction from being a leftover, its status as an effect strictly implies $^{20}$ the bygone linguistic system it presents. Obviously, the reverse does not follow: The bygone linguistic system does not imply this specific materialization of it; but it does imply that there must be some materialized expressions - just like the book found in some archive or the carved stone found in an archeological excavation.

The assumption about the logical inseparability of present effects and past events, which I find in Lewis, prevents his theory of knowledge from transforming the object "into some incognizable ding an sich" (Lewis 1929: 151). Furthermore, it sets the boundaries which condition the possibilities of knowledge of the past. As already quoted above, "[t]he totality of such effects quite obviously constitute[s] all of the object that is knowable" (Lewis 1929: 151), which means that if all effects have been detected, no further knowledge is possible than that which can be gained from these effects. But if more effects occur, there is more to be known. It is of course hard to say when exactly the point of exhaustion is met, therefore a "for the time being" clause is usually advisable. But in many cases it is easy to see that there is a limited number of detectible effects, for instance if there is only one document in a certain language no one speaks anymore, or if wide portions of a collection were destroyed so as to restrict the respective research and possible knowledge about it to only a few relicts. In any case, it is not necessary to actually exhaust "all of the object that is knowable" in order to have true knowledge of a past event ${ }^{21}$ since partial knowledge already is knowledge. Furthermore, relevant knowledge - relevant in terms of an answer to a specific question asked about the object is partial by definition, because not everything that is knowable, but only certain aspects of it, can contribute to the purpose of answering a given question. or effects are 'there' at a later date to be experienced" (Lewis 1929: 152) stops short of 
explaining how these effects of the past are identified in the first place. Lewis concedes that his account would have to reveal "by analysis of experience, those peculiar characteristics by which the pastness of a thing is presently identified" (Lewis 1929: 153), but confines himself to the statement of principles, which is perfectly apt for an epistemological outline. On this in principle level it is sufficiently clear that knowledge of the past, attained by means of present effects, includes the knowledge that the object known is itself in the past. In other words, it is "known through a correct interpretation of something given, including certain given characters which are the marks of pastness" (Lewis 1929: 153). To treat something as a characteristic of pastness is an assumption made in the course of inquiry and, as always, to be verified by the anticipated proof of further experience.

Consequently, knowledge about the past is first and foremost the knowledge of something as being a sign or characteristic of the past - which means that the basic cognitive function in this respect is the assignment of a temporal locus from the point of view of a present situation..$^{22}$ Within that situation the characteristics of the past are by no means "transempirical," but concretely present and experienced. For Lewis the past is everything but the abstract sum of the strictly bygone; it is precisely what has left all those traces behind which can now be taken as the starting point and evidence for asking questions about the "nature" of this very past. Based on these traces (or marks of pastness, as Lewis says) there is no mystery in claiming that the past can be and must be anticipated - not as something to happen, but as something to be known. Accordingly, if retrospection shall be used as a name for justified knowledge of the past, as Lovejoy promoted, it cannot mean an unqualified attempt to "look back," but rather the process of hypothesizing: making well-grounded assumptions and using the evidence at hand to inferentially prove these right or wrong, always aiming at further proof and always ready for revision. In short, if retrospection means knowledge (and not just contemplation) it is really anticipation.

To sum up the major insights about knowledge of the past to be drawn from Lewis' theory: The past is extending into the present ${ }^{23}$ by means of its enduring effects which are identifiable by certain marks of pastness (while leaving open how these marks are identified concretely). The past can be known by using these material extensions as evidence for assumptions which await future corrections or proof. Since Lewis left open the more concrete conditions of the process in which knowledge of the past is gained, I will now turn to Edgar Wind's contribution on history as inquiry. Wind not only complements Lewis' epistemological achievement, but also draws some resolute consequences concerning the interdependent relationship between the past as extending into the present and the past as something to be reconstructed by intruding into it. These consequences concern especially the difference a past situation will make in the future.

\section{Edgar Wind on Historical Inquiry: Intruding into the Past (and its Future)}

What, then, are the specific features of the knowledge-experience that is attained in historical inquiry? According to Edgar Wind, the general way in which knowledge is gained in the modes of history and natural science is indeed the same. And this holds not only in principle, but to a certain extend even in practice; it only differs in terms of the material items used as tools in the process of inquiry. 

philosopher and later became an art historian in the Warburgian style of Kulturwissenschaft (and the first to become professor of art history at the University of Oxford). After receiving his PhD from Hamburg University, where he studied with Ernst Cassirer and Erwin Panofsky, Wind moved to the United States where he spent four years (between 1924 and 1928) working as a teacher in New York and as a lecturer of philosophy at the University of North Carolina at Chapel Hill..$^{24}$ During this time, he became closely acquainted with the American philosophical scene of the 1920s and especially with the pragmatist tradition. He was strongly impressed by the writings of Charles S. Peirce which were just made available by Morris R. Cohen's famous edition Chance, Love, and Logic from 1923. Peirce's essay on "How to Make Our Ideas Clear" became something of a model for Wind's book about Experiment and Metaphysics, ${ }^{25}$ which he wrote after returning to Hamburg. In 1926 Wind attended the Sixth International Congress of Philosophy at Harvard University where he presented a paper which set out the principles presented in his later book. Among the many renowned philosophers who attended this congress (including Dewey, Whitehead, Weyl, Hartmann, Lévy-Bruhl, Croce and many more) were also Lovejoy and Lewis, although the latter did not give a presentation at the congress. ${ }^{26}$ Lovejoy spoke about "The Meaning of 'Emergence' and its Modes" (1927) in a session on emergent evolution to which Wind later refers in his own discussion of constancy and emergency. ${ }^{27}$ However, it is not clear to what extent Wind engaged with Lovejoy's work ${ }^{28}$ and if he took any notice of Lovejoy's earlier criticism of the pragmatist theory of knowledge. By contrast, the influence of Lewis is more evident since Wind directly refers to Lewis' paper on "The Pragmatic Element in Knowledge" (1970c), which is an earlier version of a central chapter of Mind and the World Order. ${ }^{29} \mathrm{John}$ Michael Krois even goes so far as to claim that Lewis' thoughts on the historically changing pragmatic conditions of a priori concepts ultimately led Wind to revise the kind of Kantianism ${ }^{30}$ that was so very strong in his home country and especially among his teachers.

Be that as it may, Wind tries to combine the pragmatic ideas he gained during his early years in America with the basic insights of the philosophy of culture as developed by his teacher Ernst Cassirer and relates these ideas to the problem of how history and cultural inquiry generate knowledge. In a paper which was included in a collection of essays presented to Cassirer at the occasion of his 60th birthday, Wind explored "Some Points of Contact between History and Natural Science" (1936). Although this paper presents a brief outline of a potentially path-breaking account on the philosophy of inquiry, which entails a bridging of the needless gap between "science" and "humanities," it had - like all of Wind's philosophical writings - almost no impact on the philosophical, historiographical, and scientific community. ${ }^{31}$

objecting to the common separation of "science" and "humanities" (or "Naturwissenschaft" and "Geisteswissenschaft"), Wind argues that both fields of inquiry entail the same mode of using epistemic instruments. The basic suggestion of Wind's position consists in the functional equation of two kinds of investigational tools, namely scientific instruments and historical documents, which are themselves part of the very matter they are "measuring." An instrument of experimental investigations into a certain sphere of the physical world, say of temperature, must itself participate in this very sphere of the physical world: it must be a physical thing which is sensitive to changes in temperature in order to be able to continuously react to such changes and be able to 
represent these on a scale. ${ }^{32}$ Likewise, the documents which are the means of historical investigations must themselves be parts of the historical world and the particular historical situation they are representing. For example, the Rosetta Stone is a presently existing physical thing that embodies a practice of translation it was once part of and thus allows for the investigation of historic encounters of Greek and Egypt ancient cultures.

Thus the process of inquiry, not only in history but also in natural science(s), ${ }^{33}$ is unavoidably circular: one must already presuppose the historical or physical situation which is investigated in order to recognize some material thing to be a part of that situation. Once such a thing has been recognized, it can be used to understand the very situation which was already presupposed. This kind of circularity - which Wind describes in detail for the experimental sciences in his outstanding book on Experiment and Metaphysics $^{34}$ - is not "vicious," meaning a mere logical mistake, but the unavoidable condition of every kind of (scientific) inquiry as conducted by the ever limited, but ever extendable human understanding. In other words, inquiry never starts from scratch, but on the grounds of what we already know, assume and presuppose. The claim to knowledge, which remains essential to the practice of inquiry, is secured by treating not only the explicit assumptions of a given research project, but virtually every supposition implied in the process as a system of hypotheses. The idea of hypothesis has to be taken very seriously in terms of testable, decidable assumptions - unlike neutral or indifferent propositions, which are not decidable, but simply die off over time. ${ }^{35}$ (This is precisely the passage where Wind, though mainly discussing Poincaré, directly refers to the aforementioned paper by C. I. Lewis.)

The functional equivalence of documents and instruments does not mean that there are no significant differences - though these differences, as Wind's paper makes very clear, are gradual, not essential. One significant difference, which is of particular interest here, concerns those aspects Lewis calls the marks of pastness. Unlike the purely technical instruments of natural inquiry, the historical documents Wind has in mind necessarily show such marks of pastness: In order to "be" historical documents they first have to be recognized as participating in a past reality, a past state of human affairs. Before the Rosetta Stone is understood as documenting a remote trilingual cultural encounter, it is a mere stone; but it becomes a document as soon as some scholar recognizes that the unusual grooves on its surface display a script, even different scripts arranged in parallel order. The scholar is able to know that because s/he already knows something about script, something about the place, where the stone was found, and especially something about the history of ancient Egypt and Greece. But furthermore, as soon as s/he uses the Rosetta Stone as a means for finally translating hieroglyphs (which s/he was until now unable to decipher) into Greek letters (which s/he already knew), this document is used as a powerful instrument of knowledge of the past.

In order to have a definition it can be stated, first, that all documents, if used in inquiry, are instruments; and second, that they are instruments of a specific kind, carrying the marks of pastness. But while all documents are (potential) instruments, the reverse does not follow. If a drilling machine that is used as an instrument in geological research is taken as a purely technical instrument for the extraction of a sample of sediments deep in the soil, it is not itself documenting anything about the past of the planet. However, the sample extracted by use of the drilling machine is clearly a document, a material extension and representation of the past and thus a (non-technical) epistemic instrument 
of knowledge of the earth's past (as well as of the subsequent present condition of the planet). In any case, the decision whether a thing is an instrument of the technical or of the documentary kind is a decision that is made in the practical use of the respective item. Even the drilling machine can become a document if it is treated as representing a certain stage in the history of engineering and of drilling in particular, or in the history of invasive methods in experimental geology (in contrast to methods of computer simulation, for instance). In other words, "instrument" is the generic term which encompasses the specific terms of technical instruments and documents. When it comes to practical decisions in the process of inquiry these different kinds of instruments are not only equivalent, they are interrelated and enhance each other: Technical instruments help identify and obtain documents that might themselves become "technical" devices (like the Rosetta Stone becomes a medium of translation), whereas the technical instruments might in turn become documents of past technologies.

Now the most striking aspect of Wind's essay becomes apparent as he asserts that "[ $t]$ he investigator intrudes into the process that he is investigating" (Wind 1936: 258). He further explains this statement as follows:

This intrusion, of which every investigator must be guilty if he wishes to make any sort of contact with his material and to test the rules of his procedure, is a thoroughly real event. A set of instruments is being inserted, and the given constellation is thereby disturbed. The physicist disturbs the atoms whose composition he wants to study. The historian disturbs the sleep of the document that he drags forth from a dusty archive. This word 'disturbance' is not to be taken as a metaphor, but is meant literally [...]. To the historian it might, indeed, sound like a metaphor if he is told that the document is disturbed by him. For involuntarily he pictures it as a material piece of paper, which does not mind whether it is lying in a cupboard or on a table. However, if we look upon it as an historical object, and consider its present status -viz. how it has been discarded and forgotten - as part of the historic process itself, then this process is indeed 'disturbed' by him who brings the forgotten words back to memory. (Wind 1936: 261)

Using the example of an unpleasant disclosure of some hero's weakness (looking on recent philosophical discussions one may think of the case of Heidegger here ${ }^{36}$ ), Wind makes clear that by disturbance he means "a factual alteration of our belief" and that "no historical inquiry is ever undertaken without the intention of creating such a disturbance" (Wind 1936: 262). So the purpose of historical inquiry is to disturb an historical situation in order to find out how this situation is like and how it has changed now that it is disturbed. This kind of disturbance is analogous to the methods of experimental physics where atoms and quanta are disturbed in order to reveal their nature, and where measurement necessarily means modification ${ }^{37}$ In this sense, a discovery is nothing but the reaction of the studied object to what is implemented into it by the investigator..$^{38}$ From this invasive (or simply experimental) concept of historical inquiry it follows that the past is neither "dead and gone," but instrumentally accessible, nor "blankly there," but needs to be disturbed in order to reveal what is there to be known about it. Both happens by means of the embodiments of a past situation (which are, as I like to put it, the material extensions of the past into the present) which serve as evidence for future findings about it. To say that the past extends and is thus accessible and real, and to say at the same time that it is not immediately given, but needs to be disclosed trough documents, amounts to a position - namely Wind's position - which bridges the gap between "instrumentalism" and "realism." Although these two "isms" are 
usually taken as counterparts in philosophical discourse, it must be acknowledged that they are deeply and necessarily intertwined. To paraphrase Wind's suggestion: The reality of the past, which is embodied in a document, is the (metaphysical) precondition for the instrumental status of this very document.

The consequences from all this for the anticipation of the past can be summarized in the following three interrelated aspects:

- Hypothesis and proof. To deploy a hypothesis about a past event is to anticipate the outcome of its proof. In other words, this means the anticipation of our future knowledge about the past and its impact on subsequent action. With Wind's paper it becomes clear how this knowledge is attained: It is developed from what the inquirer already knows and what $\mathrm{s} / \mathrm{he}$ for this reason assumes in a methodically justifiable manner, which means to introduce a hypothesis into the circle of inquiry in order to change what s/he already knows. Since the methodical justifiability relies on the documents as pars pro toto and evidence of the past, the hypothesis - the question whether the assumption is correct - is invested into these documents as epistemic instruments.

- Anticipating the present as becoming past. If there are extensions of the past into the present, it is also clear that the present will extend into the future and will thus become past. To treat the present by anticipating its future pastness is to take the historical standpoint towards the present. This loop of the self-reflective circle is not explicitly discussed in Wind's paper, but it is an obvious consequence of his argument: Anticipating the future discovery of a present situation means to reckon not only with its enduring consequences, but also with its disturbance and re-evaluation in the light of the now unapparent evidence, which will survive. One might regard this as a specifically ethical implication of anticipating the (present as) past, ${ }^{39}$ but it also articulates an epistemological insight: In contrast to the idea that the past was widely inaccessible, because it is gone, this perspective makes clear that the present will first be understood as soon as it is ceases to be present, i.e. as soon as one can take distance towards it, which is a precondition for knowledge altogether. ${ }^{40}$

- Anticipating the transformation of ourselves. Wind's position not only bridges the assumed gap between natural science and history, showing that the latter is as much a science as the former, both equally entangled in hermeneutic circles; he also aims at linking the theory of knowledge, as derived from these modes of inquiry, to the problem of cultural self-reflection and the self-transformation of human kind ${ }^{41}$ This truly pragmatist attitude is supported by his claim that historical inquiry is always guided by the intention to disturb. Historical inquiry is in other words driven by the anticipation of the effects its discoveries will have on the conduct of social life, as it intrudes into the self-conception of a social group. It not only reckons with the past to be a different past in the future, it also anticipates that as the past changes, "we" change (whereas "we" means simply those who are affected by it). For example: As soon as we find out about the influence some anti-democratic forces had on the very democratic constitution we are the heirs and adherents of, this changes our position within such a legacy and we suddenly become different democrats. However, these changes may not always come up as a shock with immediate dramatic consequences, they may also appear as rather slight alterations - still they are changes caused by inquiring the past.

Finally, the paradox of the claim that the past is anticipated vanishes completely as soon as this claim is supported by what Wind calls the configural progression of time. Wind articulates this concept ${ }^{42}$ mainly in negative terms as opposed to the dominant idea of linear progression according to which time is regarded as a continuous, mechanical unfolding of strictly consecutive stages. Positively defined, configural progression means 
the constant reshaping of relations in time and accounts for possibly overlapping sequences (instead of discrete stages). It thus allows us to conceive of time structures which are internal to the phenomena of a given investigation, be it in history or modern physics, and gives a "sense for periodicity" ${ }^{43}$ which is omitted in the externalist concept of linear time. A concept like this is necessary in order to account for the emergent symbolic interrelations of historical (as well as physical) events, and also for the specific conditions under which a past meaning or figuration "survives" 44 and is transformed in and through cultural changes and the intrusions of investigators. A linear concept, based on the idea of causal "chains," is simply unfit for this task. This is precisely what Lovejoy did not see in his criticism of the anticipatory concept of knowledge which was ultimately based on the linear understanding, thus committing what can be called the fallacy of linear time progression. ${ }^{45}$

Wind's concept of the configural progression of time comprises his understanding of the vibrant debate on "emergence" following Samuel Alexander's and C. Lloyd Morgan's (and later also Whitehead's) engagements into this subject-matter, and which was discussed by Lovejoy in the aforementioned talk at the congress in $1926 .{ }^{46}$ The reference to emergence is crucial for the configural concept because it opens the path for an understanding of how certain past, present and future events enter into configurations which create meaning and have consequences - not because they strictly follow (from) each other, but because they affect each other and thus create a specific new situation. It also introduces (epistemic) chance and (ethical) freedom, "diversity of alternatives" and "the recognition of different degrees of reliance" in acting, ${ }^{47}$ or simply contingency as undeniable factors of progression.

Thus, the configural concept of time makes conceivable the many ways in which past, present, and future are closely intertwined instead of being mere successions of time fractions. Based on this concept, historical inquiry appears to be concerned with the consequences which emerge from disturbing a past event and from bringing it into new epistemic constellations. In this way it is recognized that different consequences of a past event make it a different kind of event, which means that the past will on the whole not stay the same. Anticipation is a prerequisite of establishing the difference the past will make in the future.

\section{BIBLIOGRAPHY}

ARENDT H., (1958), “The Modern Concept of History,” The Review of Politics, 20/4, 570-90.

ARMStrong A. C., (1908), "The Evolution of Pragmatism," The Journal of Philosophy, Psychology and Scientific Methods, 5/24, 645-50.

BOODIN J. E., (1909), "What Pragmatism is and is not," The Journal of Philosophy, Psychology and Scientific Methods, 6/23, 627-35.

BREDEKAMP H., (1998), “Falsche Skischwünge. Winds Kritik an Heidegger und Sartre / Anhang: Edgar Winds Kritik an Heidegger und Sartre und die Reaktionen," in H. Bredekamp, 
B. Buschendorf, F. Hartung \& J. M. Krois (eds.), Edgar Wind. Kunsthistoriker und Philosoph, Berlin, Akademie Verlag, 207-26.

BUSCHENDORF B., (2000), "Nachwort von Bernhard Buschendorf: Das Prinzip der inneren Grenzsetzung und seine methodologische Bedeutung für die Kulturwissenschaften," postface in Wind (2000).

DANTO A. C., (2007), Narration and Knowledge, New York, Columbia University Press.

DEWEY J., (1910), “A Short Catechism Concerning Truth," in The Influence of Darwin on Philosophy and Other Essays in Contemporary Thought, New York, Henry Holt and Company, 154-68.

DEWEY J., (1917), “The Need for a Recovery of Philosophy," Creative Intelligence. Essays in the Pragmatic Attitude (by John Dewey, Addison W. Moore, Harold Chapman Brown, George H. Mead, Boyd H. Bode, Henry Waldgrave Stuart, James Hayden Tufts, Horace M. Kallen), New York, Henry Holt and Company, 3-69.

DEWEY J., (1922), “Realism without Monism or Dualism, I. Knowledge Involving the Past," The Journal of Philosophy, 19/12, 309-17.

DEWEY J., (1958), Experience and Nature, New York, Dover (imprint of second edition from 1929). DEWEY J., (2004), Essays in Experimental Logic, New York, Dover (imprint of first edition from 1916). HARTMANN N., (1949), Das Problem des geistigen Seins. Untersucheungen zur Grundlegeung der Geschichtsphilosophie und der Geisteswissenschaften, Berlin, De Gruyter (second edition, first edition: 1932).

HOLT H. et. al., (1912), The New Realism. Cooperative Studies in Philosophy by H. Holt, W. T. Marvin, W. P. Montague, R. B. Perry, W. B. Pitkin, \& E. G. Spaulfing, New York, Macmillan.

HOоK S., (1927), The Metaphysics of Pragmatism, Chicago, Open Court.

KROIS J. M., (2011), “Kunst und Wissenschaft in Edgar Winds Philosophie der Verkörperung," in H. Bredekamp \& M. Lauschke (eds.), Bildkörper und Körperschema. Schriften zur Verkörperungstheorie ikonischer Formen, Berlin, Akademie Verlag, 3-23.

LEWIS C. I., (1918), A Survey of Symbolic Logic, Berkeley, University of California Press.

LEWIS C. I., (1929), Mind and the World Order. Outline of a Theory of Knowledge, New York et al., Charles Scribner's Sons.

LEWIS C. I., (1970a), "Pragmatism and Current Thought (1930)," in Collected Papers of Clarence Irving Lewis, edited by J. D. Goheen and J. L. Mothershead Jr., Stanford, Stanford University Press, 78-86. LEWIS C. I., (1970b), “A Pragmatic Theory of the A Priori (1923)," in Collected Papers, 231-9.

LEWIS C. I., (1970c), “The Pragmatic Element in Knowledge (1926)," in Collected Papers, 240-57.

Lovejoy A. O., (1908a/b), “The Thirteen Pragmatisms," in The Journal of Philosophy, Psychology and Scientific Methods, 5/1, 5-12 (a) and 5/2, 29-39 (b).

Lovejoy A. O., (1909), "Pragmatism and Realism," in The Journal of Philosophy, Psychology and Scientific Methods 6/21, 575-80.

Lovejoy A. O., (1920), "Pragmatism Versus The Pragmatist," in Essays in Critical Realism. A Cooperative Study of the Problem of Knowledge by D. Drake, A. O. Lovejoy, J. B. Pratt, A. K. Rogers, G. Santayana, R. W. Sellars, \& C. A. Strong, London, MacMillan and Co., 35-81.

LOVEJoY A. O., (1924), “Pastness and Transcendence," The Journal of Philosophy, 21/22, 601-11. 
Lovejoy A. O., (1927), “The Meaning of 'Emergence' and its Modes," in Proceedings of the Sixth International Congress of Philosophy, edited by E. S. Brightman, New York, Longmans, 20-33.

LOVEJoy A. O., (1930), The Revolt Against Dualism. An Inquiry Concerning the Existence of Ideas, Chicago, Open Court.

LOVEjoy A. O., (1936), The Great Chain of Being. A Study of the History of an Idea, Cambridge, Mass., Harvard University Press.

MEYER M., (1908), “The Exact Number of Pragmatisms," The Journal of Philosophy, Psychology and Scientific Methods, 5/12, 321-6.

MONTAGUe W. P., (1909), “May a Realist be a Pragmatist?," The Journal of Philosophy, Psychology and Scientific Methods, 6/17, 460-63 (I.); 6/18, 485-90 (II.); 6/20, 543-48 (III.); 6/21, 561-71 (IV.).

RydENFELT H., (2009), "The Meaning of Pragmatism: James on the Practical Consequences of Belief," Cognitio, 10/1 (São Paulo), 81-9.

VAN FRAASSEN B. C., (2008), Scientific Representation: Paradoxes of Perspective, Oxford, Oxford University Press.

WIND E., (1927), "Experiment and Metaphysics," in Proceedings of the Sixth International Congress of Philosophy, edited by E. S. Brightman, New York, Longmans, 217-24.

WIND E., (1932/33), "Grundbegriffe der Geschichte und Kulturphilosophie," typescript of lectures held at Hamburg University, in Edgar Wind Papers, Bodleian Library, University of Oxford, MS. Wind 154, folder 2.

WIND E., (1936), "Some Points of Contact between History and Natural Science," in Philosophy and History. Essays presented to Ernst Cassirer, edited by R. Klibansky \& H. J. Paton, Oxford, Clarendon Press, 255-64.

WIND E., (2000), Das Experiment und die Metaphysik. Zur Auflösung der kosmologischen Antinomien, edited and with a postface by B. Buschendorf, introduced by B. Falkenburg, Frankfurt a. M., Suhrkamp (first published in 1934).

WIND E., (2001), Experiment and Metaphysics. Towards a Resolution of the Cosmological Antinomies, translated by C. Edwards, introduced by M. Rampley, Oxford, Legenda (European Humanities Research Center).

\section{NOTES}

1. Cf. Lovejoy 1924; in fn. 1 Lovejoy summarizes the preceding papers which constitute the debate.

2. Cf. Rydenfelt 2009, who defends James against Lovejoy's reproaches.

3. This bold attempt did of course not remain uncontested. Explicit reactions appeared immediately, be it in the form of a counter attack, as for example in a paper by Max Meyer (1908), or by accepting the challenge for an analysis of the evolution of pragmatism, like in A. C. Armstrong's paper on the matter (1908) - or both at the same time as in J. E. Boodin (1909). Lovejoy's controversial criticism of pragmatism also flowed into another debate, which concerned the relation of pragmatism and realism. This debate was initiated by a series of papers under the titular question "May a Realist be a Pragmatist?" by William P. Montague - a prominent advocate of the "new realism" - which were published in The Journal of Philosophy in 1909. 
4. It was published as a chapter in a book entitled Essays in Critical Realism. A Co-operative Study of the Problem of Knowledge. The treatises included in this volume document the cooperative project of a group of renowned American philosophers (namely Durant Drake, James Bissett Pratt, Arthur K. Rogers, George Santayana, Roy Wood Sellars, C. A. Strong and Lovejoy), who aimed at launching a "critical" (though non-Kantian) period of realism in the United States, reacting to an earlier volume by the "new realists" (Holt et al. 1912).

5. Lovejoy seems to construct a space of philosophical doctrines, in which the polar distinction of monistic and dualistic positions intersects vertically with the distinction of realistic and idealistic doctrines.

6. Cf. Lovejoy (1920: 51-3).

7. Cf. Lovejoy (1920: 53).

8. In his quotation of this passage from Dewey, Lovejoy fails to give quotation marks Dewey puts around the word "categories," thus indicating that he is using the term rather as a metaphor.

9. Although Lovejoy later introduced his "analytic" method of the history of ideas, which treats ideas as distinct units, which are (re-) combined with each other in the course of history, even this method does not work on the grounds of a past, which is "blankly there," but one which has to be reconstructed and interpreted; a past, in which ideas, even as units, have contexts in various fields of connections, uses, and connotations. So fortunately Lovejoy at least practically discards this pseudo-realist notion of the past.

10. Sidney Hook's The Metaphysics of Pragmatism gives a clear account of pragmatism as instrumentalism, drawing from Peirce and Dewey, while rejecting James' (and F. C. S. Schiller's) views. Cf. Hook (1927: esp. 9).

11. Quoted in Lovejoy (1920: 66).

12. Cf. Dewey (1910: 160-1).

13. Charles Lyell (1797-1875), British geologist, author of Principles of Geology (1830-33).

14. Cf. Dewey (1910: 162); and Lovejoy (1920: 68).

15. The "Catechism" even includes a very infelicitous remark on "the personal milk" the pragmatist had spilled "in the absolutist's cocoanut" which cannot avoid supporting Lovejoy's complaint about the "subjectivistic strain." See, Dewey (1910: 168).

16. He also tries to make the problem about the decision between monism and dualism - which is what Dewey takes up in response to Lovejoy, cf. Dewey 1922.

17. Cf. for example Lewis (1929: 167).

18. Lewis is famous for introducing the term "qualia" which, however, can already be found in Peirce.

19. Cf. Lewis (1929: 271-2).

20. The theorem or system of strict implication was established by Lewis in his Survey of Symbolic Logic (1918). Given the complexity of Lewis' formal analysis of strict implication my reference to it is rather superficial. I am using the term in the general sense that it is impossible that $p$ (the effect) and not $q$ (the event).

21. Such a claim to exclusive truth is an exaggeration of a certain kind of idealist epistemology, cf. Lewis (1929: 150).

22. Cf. Lewis (1929: 151).

23. By this phrase I am alluding to Nicolai Hartmann who uses the term "Hineinragen." Cf. Hartmann (1949: esp. 546). Although Hartmann's account would be very useful in this context, it will have to be discussed elsewhere.

24. Wind spent another extended period of his life in the USA as he became professor of art and philosophy first at the University of Chicago (1942-1944) and then at Smiths College in Northampton (1944-1955) before moving to Oxford.

25. Cf. Wind (2001: 6). 
26. The attendance of Lewis, who at the time was a professor at Harvard, is asserted by Krois (2011: 11).

27. Cf. Wind (2001: 113, fn. 89).

28. Although this is strongly suggested by Buschendorf (2000: 298-9).

29. Cf. Wind (2001: 32).

30. Cf. Krois (2011: 11-2). Krois assumes that Wind already knew Lewis' paper "A Pragmatic Conception of the A Priori" from 1923 (1970b) - which is indeed quite likely.

31. Surprisingly, Hannah Arendt acknowledges the merits of Wind's argument in a footnote of her paper on "The Modern Concept of History" from 1958, where she remarks: "It seems strange that so fundamental and obvious an argument [like Wind's] should have played no role in the subsequent methodological and other discussions of historical science" Arendt (1958: 590). Many thanks to Sascha Freyberg for calling my attention to this passage.

32. For a contemporary account on the complex history and logic of the thermometer cf. van Fraassen (2008: 115-39, esp. 125-30), where van Fraassen gives his interpretation of Mach's account.

33. For some reason Wind uses the singular, natural science, perhaps in order to rhetorically stage the presumed contrast between historical and "scientific" investigation.

34. After this book got Wind his Habilitation at the University of Hamburg under Ernst Cassirer and Ernst Panofsky in 1929, it was first published in 1934. Being neglected over many decades, it only reappeared in 2000 and was published in an English translation in 2001.

35. Cf. Wind (2001: 31-3).

36. Wind expressed his own criticism on the Heideggerian legacy in a polemic piece entitled "Jean-Paul Sartre, A French Heidegger," which is included as an appendix in Bredekamp 1998.

37. Cf. Wind (1936: 261-2).

38. This principal of hermeneutics, which applies to natural science and history alike, Wind puts as follows: "[I]n a competition between science and history, the historians would be sure to score one point: in dealing with their symbols, they have long realized, what the physicist, dazzled by the polished appearance of their equations, have only recently noticed; namely, that every discovery regarding the objects of their inquiry reacts on the construction of their implements; just as every alteration of the implements makes possible new discovery" (Wind 1936: 262).

39. By coincidence, Jürgen Habermas recently emphasized the importance of taking the future historians view on current developments, while reflecting (mostly) on the Brexit vote in an interview on Die Zeit (Nr. 29/2016, 7. Juli 2016): “Of course, it's only with hindsight that you learn there could have been another way. But before throwing away an alternative before it's even been attempted one ought to try and imagine our current situation as the past present for a future historian." The quotation is taken from the English translation (by David Gow, with the author's approval), which is on: [socialeurope.eu/2016/07/core-europe-to-the-rescue/].

40. Arthur C. Danto has argued for a similar position, cf. Danto (2007: esp. 342-63).

41. Cf. Wind (1936: 263-4).

42. Cf. Wind (2001: 97-115), as well as the typescript of his last lectures in Hamburg on the foundational concepts of history and the philosophy of culture from 1932/33 which is stored in the Bodleian Library in Oxford (MS. Wind 154, folder 2). A widely convincing interpretation of Wind's configural concept with extensive quotations from the lecture-typescript is presented by Buschendorf (2000: 295-301).

43. "Konfig[uraler] Zeitbegriff gibt [ein] Gefühl für Periodizität."

44. This concerns what in the Warburgian tradition - of which Wind became one of the prominent proponents - is called "Nachleben." For a reference to Warburg in the context of configural time cf. Wind (1932/33: 18).

45. Wind considers the linear concept only as an impossible limit case of configural time, as a certain kind of ideal configuration. Cf. Wind (2001: 104-5). 
46. From a Windian perspective Lovejoy's acknowledgment of emergence (and the useful distinctions he made within that concept) should lead him towards a configural understanding which he did not (yet) have when criticizing the anticipatory concept of knowledge.

47. "Die histor[ische] Geschichte sieht Vielfältigkeit der Alternativen. [...] Labilität also führt zur Anerkennung dieser versch[iedenen] Grade der Verbindlichkeit” (Wind 1932/33: 27).

\section{ABSTRACTS}

In this paper I argue that, from a pragmatist point of view, to know the past means to anticipate it. Accordingly, historical inquiry is directed towards the future, namely the future of the past as known. I develop this argument in three steps: (I.) Starting with A. O. Lovejoy's criticism of Dewey's anticipatory theory of knowledge I defend the basic claim that all knowledge, including knowledge of the past, is anticipatory (i.e. directed at future consequences). Lovejoy's criticism shows that Dewey's statements invite misunderstandings, which have to be removed. (II.) I then turn to C. I. Lewis' enhanced outline of a pragmatist theory of knowledge. Lewis provides epistemological arguments regarding the structural features of knowledge of the past and argues knowledge that is gained by the past's present effects. (III.) Finally, I turn to a notable essay by E. Wind in which he stresses the intrusive and future-oriented character of historical inquiry: Documents are used as instruments for intruding into the past, asking how the past will be understood in the light of new or reconsidered evidence. This process involves anticipating the effects that a different past will have on those affected by the history in question.

\section{AUTHOR}

\section{STEFAN NIKLAS}

University of Oxford / Universität zu Köln

mail[at]stefanniklas.de 